\title{
Development and Validation of prediction for estimating resting energy expenditure in Indian subjects.
}

\author{
Ghazala Perveen Khan ${ }^{1}$, Munna Khan ${ }^{2}$, Shabana Mehfuz ${ }^{3}$ \\ ${ }^{1,2,3}$ Department of Electrical Engineering, Jamia Millia Islamia University, New Delhi, India. \\ Corrosponding Auther: Ghazala Perveen Khan
}

\begin{abstract}
Assessment of energy intake and expenditure is an important criteria for nutrition care plan. Equation for predicting Resting Energy Expenditure (REE) or Resting Metabolic Rate (RMR) is based on body weight, height, sex and FFM. Resting Energy Expenditure (REE) is an important parameter, which estimate metabolic rate in obese and underweight individuals. Different formulas are used to estimate energy requirements in Indian health clinics. But to our no precise study has has been done in this area, so far. The aim of the present paper was to develop and predict Resting Energy Expenditure, for Indian subjects. For this 100 Indian subjects, participated in the study whose Human Body composition parameters, like sex, Impedance, RMR, BMI (Basal Metabolic Index), were measured experimently by Maltron-II Body composition Analyser. Two different sets of Resting Energy Equations were developed. First with sex, age, weight and Impedance Index at different frequencies of $5 \mathrm{KHz}, 50 \mathrm{KHz}, 100 \mathrm{KHz}$ and $200 \mathrm{KHz}$. Second with independent variables as FM, FFM and age and sex.The results obtained were then validated with the Maltron-II Body composition analyser and it was found that the results were in close proximity with the results obtained from instrument. In addition to this statistical Analysis of the data is carried out with the help of statistical software $R$ version (2.9.2) which is useful to study the correlation obtained from the the Instrument, and that obtained by scientists. Further different other parameters of statistics is formulated in tabular form.
\end{abstract}

Keywords: Bio Electrical Impedance Analysis, Body composition models, Body density (BD), Fat mass, Fat Free Mass (FFM), Resting Energy Expenditure (REE), Body Mass Index(BMI).

\section{Introduction:}

Assessing the energy intake and expenditure by cohorts of individual of a particular country is the need of the hour. It helps in nutritionist giving the hazy idea about the general scenario of eating habits and disorders about the particular group of individuals. Generally, we use indirect calorimetry to measure REE or RMR. However, for this paper we have used, Bio Electrical Impedance Analyser to measure the RMR or REE. And develop REE through Multiple Regression Analysis. Since the beginning of the $20^{\text {th }}$ century, several authors have tried to address the by developing equations for predicting REE in children and adolescents on the basis of anthropometric and body composition parameters (Harris and Benedict, 1919; Schofield, 1985; World Health Organization, 1985; Tverskaya et al. 1998; Derumeaux-Burel et al.2004). As discussed in abstract above, we have seen that for the majority of people, RMR constitutes almost $60-70 \%$ of total energy expenditure and hence is used for estimation of energy requirement of populations. The REE is useful to prevent under and overfeeding of individuals. Excessive calories or inadequate feeding regimens can have detrimental effects on clinical outcomes of patients' care. Malnutrition can result from feeding a patient less than his/her metabolic requirements leading to reduced respiratory muscle strength, increased risk of infection, poor wound healing and impaired normal body function. Overfeeding means providing too many calories that cannot be used by the body and are therefore converted to fat storage. This can cause more $\mathrm{CO} 2$ to be produced and result in increased work of breathing.

In India when it comes to general health of people there is a large disparity between urban elite class and rural class. Obesity is becoming a factor in many nations around the world. According to latest obesity statistics, sponsored by International Day of Evaluation of Abdominal Obesity; 75 percent of Indian women and 58 percent of Indian men are obese. Besides this, numerous studies indicate that malnutrition is another serious health concern that Indian subject face (Chatterjee, 1990; Desai, 1994; The World Bank, 1996). It threatens their survival as well as that of their children. The negative effects of malnutrition among women are compounded by heavy work demands, by poverty, by childbearing and rearing, and by special nutritional needs of women, resulting in increased susceptibility to illness and consequent higher mortality. Attention must therefore be paid to determine the body composition of females so that appropriate measures can be taken if women in India are facing abnormality in their health due to their abnormal nutritional status.

The purpose of the current study was to use the body composition of Indian subjects database to develop and predict two sets of equation ;REE using independent sets of variable sex, age weight and Stature of body at the frequencies of $5 \mathrm{KHz}, 50 \mathrm{KHz}, 100 \mathrm{KHz}, 200 \mathrm{KHz}$.The other set of REE is developed using sex, age, 
FFM, FM ;so that, a general idea about the health status of Indian subject.REE using can be developed and predicted using multiple regression analysis, and for that purpose $\mathrm{R}$ (2.9.2) version is used. . The obtained equations are of the form:

$\operatorname{REE}_{(\mathrm{fl}, \mathrm{f2}, \mathrm{fz}, \mathrm{f4})}=\mathrm{a}_{0} \mathrm{Sex}+\mathrm{a}_{1}$ Age $+\mathrm{a}_{2}$ Wt. $+\mathrm{a}_{3} \mathrm{Z}_{\mathrm{I}(\mathrm{fl}, \mathrm{ft}, \mathrm{f3}, \mathrm{f4})}+\mathrm{C}_{1}$ $\mathrm{REE}=\mathrm{b}_{0}$ Sex $+\mathrm{b}_{1}$ Age $+\mathrm{b}_{2}$ FFM. $+\mathrm{b}_{3} \mathrm{FM}+\mathrm{C}_{2}$

Where $\mathrm{REE}_{(\mathrm{fl}, \mathrm{fz}, \mathrm{f3}, \mathrm{f4})}$ is the Resting Energy Expenditure of individual at the frequency of $5 \mathrm{KHz}, 50 \mathrm{KHz}, 100 \mathrm{KHz}$ and $200 \mathrm{KHz}$.REE is Resting Energy Expenditure at constant frequency . $\mathrm{C}_{1}$ and $\mathrm{C}_{2}$ are intercepts of equation (1) and (2) respectively and $\mathrm{a}_{0}, \mathrm{~b}_{0}$ are coefficients multiplied by sex variable of equation(1) and(2) respectively and $a_{1}, b_{1}$ are coefficients multiplied by age variable of equation(1) and(2) respectively. $a_{2}$ is the coefficient multiplied by Impedance Index at frequency of $5 \mathrm{KHz}, 50 \mathrm{KHz}, 100 \mathrm{KHz}$ and $200 \mathrm{KHz} . \mathrm{b}_{2}$ is the coefficient multiplied by FFM and $b_{3}$ multiplied by FM component of the subject.

\section{Literature survey:}

\section{Materials and methods:}

A lot of scientists have been contributing in the past, for the development of body composition prediction equations for cohorts of individual belonging to different ethnic groups, age groups, sex and according to their level of physical activity. A lot of scientist has been researching in the field of Resting Energy Expenditure and it has been found that prevalence of obesity is due to the mismatch between Energy intake and Energy expenditure. It has been found that higher REE of obese subjects is mostly related to high FFM and FM. Lazzer et. al in 2003, studied the assessment of energy expenditure associated with physical activities in freeliving obese and nonobese adolescents. Lazzer et. al in 2004 observed that, a weight reduction program preserves fat-free mass but not metabolic rate in obese adolescents. Lobstein et.al in 2003 observed the prevalence of overweight amongchildren in Europe. Molner et.al in 1997 observed the effect of resting metabolic rate in children and adolescents. Bouchard and Blair in 1999 introduced comments for the consensus on physical activity and obesity. Flatt in 2001, researched on Macronutrient composition and food selection. Ekeland in 2002 saw that Physical activity but not energy expenditure is reduced in obese adolescents: a casecontrol study. A lot of scientists have been researching in the field of Resting Energy Expenditure, as it is an important field of research for nutritionlist and dietist to control malnutrition and obesity. This paper concentrates on cohorts of Indian subjects, and general trends in their eating habits. To the best of our knowledge there were no published height weight prediction equations validated on Indian subjects. The purpose of the study was therefore to develop 2 sets of REE equation, sex combined prediction equation for REE at different frequencies of $5 \mathrm{KHz}, 50 \mathrm{KHz}, 100 \mathrm{KHz}$ and $200 \mathrm{KHz}$ for Indian subjects and REE equation developed using FFM and FM as independent variable, through careful analysis of data.

\section{Subjects and Procedure:}

Human Body Composition data of 100 subjects (49males and 51 females) within the age group of 23 yrs to 50 yrs were studied through Maltron-II Body Composition Impedance Analyzer method; where excitation current of $800 \mu \mathrm{A}$ at different frequencies of $5 \mathrm{KHz}, 50 \mathrm{KHz}, 100 \mathrm{KHz}$ and $200 \mathrm{KHz}$ were applied to the source or drive distal electrodes on the hand and foot; and the voltage drop due to impedance is detected by sensor electrodes on the wrist and ankle. These human Body composition data were then utilized to calculate the Impedance Index i.e. (height ${ }^{2} /$ impedance) at different frequencies of $5 \mathrm{KHz}, 50 \mathrm{KHz}, 100 \mathrm{KHz}$ and $200 \mathrm{KHz}$. The calculated impedance index of each individual at different frequency is formulated in the form of Table (1). Finally multiple regression analysis of these data was carried out to develop and design a linear model with the help of R software (version 2.9.2), taking Impedance Index, weight, sex, height and age as independent variable and REE. Two sets of REE were developed. One; taking FFM and FM as independent variable, the other that predicted REE at different frequencies. For this, an algorithm was developed and statistical analysis of the data was done; the flow chart showing the actual process carried out to generate the linear model and Descriptive statistics is shown below in fig. (1) and Table (1) respectively.

FM = Fat Mass, FFM = Fat Free Mass, REE = Resting Energy Expenditure. Stature is represented as Zi. So; Zi at $5 \mathrm{KHz}, \mathrm{Zi}$ at $50 \mathrm{KHz}, \mathrm{Zi}$ at $100 \mathrm{KHz}$ and $\mathrm{Zi}$ at $200 \mathrm{KHz}$ are Impedance Index or Stature i.e.(height $\mathrm{T}^{2} / \mathrm{Impedance}$ ) at $5 \mathrm{KHz}, 50 \mathrm{KHz}, 100 \mathrm{KHz}$ and $200 \mathrm{KHz}$ respectively.

\section{Prediction Equation developed:}

The obtained equations are of the form:

$\mathrm{REE}_{\mathrm{fl}, \mathrm{f2}, \mathrm{f3}, \mathrm{f4}}=\mathrm{a}_{0} \times \mathrm{Sex}+\mathrm{a}_{1 \times} \times \mathrm{age}+\mathrm{a}_{2} \times \mathrm{Wt} .+\mathrm{a}_{3} \times \mathrm{Zi}_{\mathrm{f} 1, \mathrm{f2}, \mathrm{f3}, \mathrm{f4}}+\mathrm{c}_{1} \ldots \ldots \ldots .(1)$

$\mathrm{REE}=\mathrm{b}_{0 \times} \mathrm{sex}+\mathrm{b}_{1 \times}$ age $+\mathrm{b}_{2 \times} \mathrm{FFM}+\mathrm{b}_{3} \times \mathrm{FM}+\mathrm{c}_{2}$

where $\operatorname{REE}_{(\mathrm{fl}, \mathrm{fz}, \mathrm{f3}, \mathrm{f4})}$ is Resting Energy Expenditure at frequencies $\mathrm{f}_{1}=5 \mathrm{KHz} ., \mathrm{f}_{2}=50 \mathrm{KHz} ., \mathrm{f}_{3}=100 \mathrm{KHz} . \mathrm{f}_{4}=200 \mathrm{KHz}$. and $Z_{I(f 1, f 2, f 3, f 4)}$ is the calculated Impedance index i.e. (height ${ }^{2} /$ impedance) of the subjects at these frequencies, $c_{1}$ 
and $c_{2}$ are intercepts of equation (1) and (2) respectively, $a_{0}, b_{0}$ are coefficients multiplied by sex variable whose value is taken as 1 for female subjects and 0 for male; $a_{1}, b_{1}$ are coefficients multiplied by variable age of the subjects measured in years, a2 is multipled by variable Weight (Wt.) of subject in $\mathrm{Kg}$. a3 is coefficients multiplied by variable Impedance index $\left(Z_{I}\right)$ of the subjects at frequencies $\mathrm{f}_{1}=5 \mathrm{KHz} . \mathrm{f}_{2}=50 \mathrm{KHz} ., \mathrm{f}_{3}=100 \mathrm{KHz} ., \mathrm{f}_{4}=200 \mathrm{KHz}$. b2 is coefficient multiplied by Fat Free Mass (FFM) of the individual and $\mathrm{b} 3$ is coefficient multiplied by Fat Mass of the subject.

\section{Results and Discussion}

The study was able to develop 2 sets of Resting Energy Expenditure (REE) equation for Indian subjects. Data used in commercial software provided 8 BIA equations; 4 taking sex, age, Wt. and Impedance index $(\mathrm{Zi})$ as independent variable at frequencies of $5 \mathrm{KHz}, 50 \mathrm{KHz}, 100 \mathrm{KHz}$ and $200 \mathrm{KHz}$. The other taking sex, age, FFM and FM as independent variable.Sex is taken as 1 for male and 0 for female. The prediction equations developed for Resting Energy Expenditure (REE) at $5 \mathrm{KHz}, 50 \mathrm{KHz}, 100 \mathrm{KHz}$ and $200 \mathrm{KHz}$ are as shown below:

$$
\begin{aligned}
& \operatorname{REE}(5 \mathrm{KHz})=129.4114 \times \text { sex }-6.8029 \times \text { age } .+5.3727 \times \mathrm{Wt} .+12.0167 \times \mathrm{Zi}_{5 \mathrm{kHz}}+857.3221 \ldots \ldots \ldots \\
& \operatorname{REE}(50 \mathrm{KHz})=91.6212 \times \text { sex-7.214 } \times \text { age. }+4.7732 \times \mathrm{Wt}+12.2167 \times \mathrm{Zi}_{50 \mathrm{kHz}}+857.0064 \ldots \ldots \ldots(2) \\
& \operatorname{REE}(100 \mathrm{KHz})=98.5121 \times \text { sex }-6.5753 \times \text { age. }+4.8403 \times \mathrm{Wt}+10.966 \times \mathrm{Zi}_{100 \mathrm{kHz}}+859.0187 \ldots .(3) \\
& \operatorname{REE}(200 \mathrm{KHz})=80.0488 \times \text { sex-7.1747 } \times \text { age } .+5.0821 \times \mathrm{Wt}+10.2702 \times \mathrm{Zi}_{200 \mathrm{kHz}}+879.9955 \ldots . .(4)
\end{aligned}
$$

In a similar pattern the prediction equation for REE was developed taking FM and FFM of individual as $n$ independent variable. The predicted equation for REE developed is as shown below:

$\mathrm{REE}=182.82 \times$ sex $-6.058 \times$ age $+9.318 \times \mathrm{FFM}-4.307 \times \mathrm{FM} .+1142.882$

where REE(5 KHz), REE(50 KHz), REE(100 KHz) and REE(200 KHz) is Resting Energy Expenditure of body of subject in $\mathrm{KCal}$ at $5 \mathrm{KHz}, 50 \mathrm{KHz}, 100 \mathrm{KHz}$ and $200 \mathrm{KHz}$ frequency respectively, $\mathrm{ZI}_{5 \mathrm{kHz}}, \mathrm{Zi}_{50 \mathrm{kHz}}, \mathrm{Zi}_{100 \mathrm{kHz}} \mathrm{Zi}_{200}$ $\mathrm{kHz}$ is Impedance index of body at $5 \mathrm{KHz}, \mathrm{KHz}, 50 \mathrm{KHz}, 100 \mathrm{KHz}$ and $200 \mathrm{KHz}$ frequency respectively in $\left(\mathrm{cm}^{2} / \Omega\right)$. Value of sex of the subject is taken as 1 for female and 0 for male subject.Wt.is the weight of the body in Kg. and age is the age of subjects in years, FM is Fat mass of the individual and FFM is Fat Free Mass of subject in $\mathrm{Kg}$. Besides, development of BIA equations; statistical analysis of the data of data was also done the results of which are tabulated in table (3).In addition to this graphical analysis of the data is shown in Fig (2), Fig (3), Fig (4), Fig (5), Fig (6), Fig (7), Fig (8), Fig (9), Fig (10) and Fig (11). These figures showed different graphical plots such as scatter matrix plot for Resting Energy Expenditure(REE) at different frequencies, normal distribution of standardized residuals, Scale location plot, Residual verses leverage plot and standardized residual verses cook's distance plot.

These plots for linear model objects give the diagnostic information about the linear model. Besides this, a comparative study of their measured and predicted Resting Energy Expenditure (REE) at the frequencies of $5 \mathrm{KHz}, 50 \mathrm{KHz}, 100 \mathrm{KHz}$ and $200 \mathrm{KHz}$ is tabulated in Table (4) and from the results it is observed that the predicted value of TBW and FFM at these frequencies are very much closer to the measured.

\section{Conclusion:}

The body composition parameters of the samples (100 subjects) measured through instrument MaltronII Body Composition Impedance Analyzer at frequencies of $5 \mathrm{KHz}, 50 \mathrm{KHz}, 100 \mathrm{KHz}$ and $200 \mathrm{KHz}$ were utilized to obtain BIA equations. To do the same; multiple regression analysis was carried out on clinical data through R (2.9.2) software. The instrument has many advantages over the analysis of body composition through other methods and is safe, rapid, portable, easy to perform and require minimum operator training. The BIA prediction equation for Resting Energy Expenditure (REE) was developed at different frequencies. These prediction equation developed in the present paper is the first REE prediction equation for REE for Indian subjects. The predicted REE each individual are very close to the one measured through instrument. The results shows that the predicted values of REE are very much closer to the one measured through the instrument. However, it is observed that at higher frequencies the results are much underestimated then the measured value. This is due to the fact that at low frequencies, the current cannot bridge the cellular membrane and will pass predominantly through the extracellular space, whereas at higher frequencies penetration of the cell membrane occurs and the current is conducted by both the extra-cellular water (ECW) and intra-cellular water (ICW). Based on these REE equations, a general idea about the dietary habits of Indian subjects can be predicted which can be utilized for variety of clinical and research applications; as information about lean tissue mass, fat tissue mass, and fractional contribution of fat makes them excellent for monitoring pharmaceutical therapy, nutritional or exercise intervention, sports training \&/or other body composition altering programs. Besides this, the information regarding the dietary habits of Indian subjects will give the pharmaceutical companies a chance to explore the change in body composition of Indian subjects before and after drug therapy. It will also provide coaches and researchers, the initial information regarding the general trends in the health status of Indian 
subjects so that they can formulate individualized training program and provide them with information about the suitable energy needs of the body so that they can achieve desirable body weight and composition.

\section{References}

[1] Bouchard C \& Blair SN (1999) introductory comments for the consensus on physical activity and obesity. Med Sci Sports Exerc 31, Suppl. 11, S498-S501.

[2] Dietz WH, Bandini LG, Morelli JA, Peers KF \& Ching PL (1994) Effect of sedentary activities on resting metabolic rate. Am J Clin Nutr 59, 556-559.

[3] Derumeaux BH, Meyer M, Morin L and Boirie Y (2004) Prediction of resting energy expenditure in large population of obese children, Am J Clin Nutr 80, 1544-1550

[4] Ekelund U, Aman J, Yngve A, Renman C, Westerterp K \& Sjostrom M (2002) Physical activity but not energy expenditure is reduced in obese adolescents: a case-control study. Am J Clin Nutr 76, 935-941.

[5] Flatt JP (2001) Macronutrient composition and food selection. Obes Res 9, Suppl. 4, 256S-262S.

[6] Goswami PN.Thesis under the supervision of Dr. Munna Khan ;Prediction and measurement of Human Body composition using Non-Invasive technique;2010.

[7] Harris JA and Benedict FG .A Biometric Study of Basal Metabolism in Man. Washington, DC: (1919) Carnegie Institute of Washington.

[8] Heyward VH, Wagner DR. .Applied Body Composition, $2^{\text {nd }}$ Edition.Champain, IL: Human Kinetics, 2004

[9] Ismail MN, Ng KK, Chee SS, Roslee R, Zawiah H. Predictive equations for the estimation of basal metabolic rate in Malaysian adults. Mal J Nutr. 1998;4:81-90.

[10] Lazzer S, Boirie Y, Bitar A, Montaurier C, Vernet J, Meyer M \&Vermorel M (2003) Assessment of energy expenditure associated with physical activities in free-living obese and nonobese adolescents. Am J Clin Nutr 78, 471-479.

[11] Lazzer S, Boirie Y, Montaurier C, Vernet J, Meyer M \& Vermorel M (2004) A weight reduction program preserves fat-free mass but not metabolic rate in obese adolescents. Obes Res 12, 233-240

[12] Lazzer S, Boirie Y, Meyer M \& Vermorel M (2005) Which alternative method to dual-energy X-ray absorptiometry for assessing body composition in overweight and obese adolescents? Arch Pediatr 12, 1094-1101.

[13] Lobstein T \& Frelut ML (2003) Prevalence of overweight amongchildren in Europe. Obes Rev 4, $195-200$.

[14] Maffeis C, Schutz Y, Zoccante L, Micciolo R \& Pinelli L (1993) Meal-induced thermogenesis in lean and obese prepubertal children. Am J Clin Nutr 57, 481-485.

[15] Mahboubeh S, Arezoo R, Mahsa J, TirangN (2011). Validity of predictive equation for Resting Energy Equations among Iranian women. Asia Pac J Clin Nutr; 20(4): 646-653

[16] Molnar D \& Schutz Y (1997) The effect of obesity, age, puberty and gender on resting metabolic rate in children and adolescents. Eur J Pediatr 156, 376-381.

[17] Muller MJ, Bosy-Westphal A, Kutzner D, Heller M. Metabolically active components of fat free mass (FFM) and resting energy expenditure (REE) in humans. Forum Nutr 2003; 56:301-3

[18] Schwartz DB: Pulmonary failure. IN Matarese LE and Gottschlich MM:Contemporary Nutrition Support Practice.Philadelphia,W. B. Saunders, Co.

[19] Schofield WN .Predicting basal metabolic rate, new standards and review of previous work. (1985) Hum Nutr Clin Nutr 39, Suppl. $1,5-41$

[20] Stefano L, Fiorenza A, Alessandra DC, Alessandro S. Development and cross validation of prediction equations for estimating resting energy expenditure in severely obese Caucasian Children and adolescents.

[21] Tverskeya R, Rising R, Brown D and Lifshitz F .Comparision of several equations and derivation of a new equation for calculat ing basal metabolic rate in obese children. J Am Coll Nutr (1998) 17, 333-336.

[22] World Health Organization .Energy and Protein Requirements: Report of Joint FAO/WHO/UNO/ Expert Consultation. (1985) .WHO Technical Report Series no.724. Geneva:WHO. 